\title{
Hemianopia, hemianaesthesia, and hemiplegia after right and left hemisphere damage. A hemispheric difference
}

\author{
R Sterzi, G Bottini, M G Celani, E Righetti, M Lamassa, S Ricci, G Vallar
}

\begin{abstract}
The incidence of somatosensory, visual half-field and motor deficits contralateral to a hemispheric lesion in a continuous series of 154 left brain damaged and 144 right brain damaged stroke patients were investigated. These contralateral disorders were more frequent after lesions of the right hemisphere. This difference cannot be attributed to a bias in patients' selection. It is suggested that left spatial neglect is the factor underlying this hemispheric difference.
\end{abstract}

(F Neurol Neurosurg Psychiatry 1993;56:308-310)

Hemianopia, hemianaesthesia and hemiplegia contralateral to a hemispheric cerebral lesion have long been considered as primary sensory and motor deficits, but may also be manifestations of left spatial neglect. ${ }^{1}$ Right brain damaged patients with left neglect, hemianaesthesia and hemianopia may have conductance skin responses ${ }^{2}$ or normal somatosensory and visual evoked potentials to stimuli they fail to report. ${ }^{3}$ By contrast, left brain damaged patients with right somatosensory or visual deficits not associated with neglect have abnormal evoked potentials. ${ }^{3}$ In right brain damaged patients left hemianaesthesia and hemianopia may thus have an important nonprimarily sensory component, whereby information that has undergone some covert processing has no access to conscious experience. ${ }^{23}$ Similarly, hemiplegia may have a non-primarily motor component. Motor neglect, the abnormal lack of use of the limbs contralateral to a cerebral lesion may mimic motor deficits. ${ }^{45}$ Motor neglect, as somatosensory and visual neglect, ${ }^{3}$ is more frequently produced by right-sided lesions. ${ }^{5}$

These observations suggest that two components (the sensory or motor disorder and neglect) may concur to produce contralateral deficits after right brain damage. In contrast, a single factor is involved after left brain damage, as the contribution of neglect is minimal or nil. If the role of the neglect component is clinically relevant, hemianopia, hemianaesthesia and hemiplegia may be more frequently associated with right sided lesions. We have confirmed this hypothesis by looking for left/right hemisphere differences in the distribution of sensory and motor deficits in a population of stroke patients studied in a community-based epidemiological survey in Italy. ${ }^{67}$

\section{Materials and methods}

The SEPIVAC study (Studio Epidemiologico sulla Incidenza delle Malattie Cerebrovascolari) was a community-based epidemiological survey of incidence and outcome of acute cerebrovascular disease in the Sixth Local Health Unit (USL 6 del Trasimeno, Umbria). The registration of patients began on 1 September 1986, and continued until 31 August 1989. The study comprised all residents in USL 6 . The methodology of the SEPIVAC study has been described in detail elsewhere ${ }^{67}$ and only the data relevant to this study are mentioned here. Any patient who may have had a cerebrovascular event was visited as early as possible by a member of the SEPIVAC team ${ }^{7}$ either in hospital or at home. Of 375 patients with a first ever stroke, 298 (145 males and 153 females) patients with unilateral cerebral stroke lesions entered this study. The remaining 77 patients were excluded from the study because they had a subarachnoid haemorrhage (15 patients), a posterior circulation stroke (25 patients), a stroke of undetermined origin (37 patients).$^{78}$ A total of 154 patients (76 males and 78 females, mean age 73.3 years) had a left hemisphere damage (LBD) and 144 patients (69 males and 75 females, mean age $72 \cdot 6$ ) a right hemisphere damage (RBD). In the LBD group 137 patients had an ischaemic and 17 haemorrhagic lesion. In the RBD group 125 patients had an ischaemic lesion and 19 haemorrhagic lesion. The patients were examined within 30 days after stroke (mean 16.7 days, median 5 days). The patients were classified as definite or probable infarction or haemorrhages. ${ }^{78}$ Definite infarctions and haemorrhages had a CT scan diagnosis within 30 days after stroke onset. Probable infarctions had an Allen score $<4$, probable haemorrhages an Allen score $>24 . .^{910}$ Two hundred and two of 262 patients had a definite infarction, and 32 of 36 patients had a definite 
haemorrhage. Level of consciousness was assessed by the Glasgow Coma Scale. ${ }^{11}$

A complete neurological clinical examination was performed, which included the assessment of muscle strength in the upper and lower limbs, of somatosensory and visual field deficits. ${ }^{12} 13$

1) Visual half-field deficits. Visual fields were examined by a confrontation test, in which patients were required to detect unilateral movements of the examiner's finger. The patients' defective detection on one side indicated a visual half-field deficit. In non cooperative patients menacing movements towards the eye from one side and then the other were used.

2) Somatosensory deficits. Position sense was assessed by moving up or down the digit (finger, big toe) of the patients, who had to communicate the direction (upwards or downwards) of the movement. The patients' failure on one side indicated a unilateral deficit. The results of the examination were classified using a three-point scale for each item (finger, big toe): $1=$ normal; $2=$ reduced sensation; $3=$ almost absent or absent sensation. The range of the total score was 2-6. Sense of pain was examined by touching with the point of a pin the patients' face, forearm and hand, leg. The patients' failure to report the pin stimulation on one side indicated a unilateral deficit. Again, a three-point scale was used to classify the deficit for each item (face, forearms and hand, leg), with a 3-9 total score range.

3) Motor deficits. Muscle strength was evaluated for face, hand, arm, and leg. The motor function of the facial nerve was assessed by inspection and by asking patients to open their mouth and to copy the examiner baring his teeth. Hand strength was examined by requiring patients to grasp the index and middle fingers of the examiner. Limb strength was assessed by requiring patients to raise their upper or lower limbs from the bed and to hold the position for about 10 seconds. The arms were flexed at $45^{\circ}$, the forearms extended and supinated, the fingers abducted. The thighs and legs were flexed at $90^{\circ}$. The patients' failure to raise one limb, or the lowering of one limb indicated a unilateral motor deficit. In stuporous or unconscious patients motor deficits were assessed by raising both limbs and letting them fall back . The patients' muscle strength was classified using a four-point scale ( $1=$ normal; $2 / 3 / 4=$ mild/moderate/severe deficit) for each item (face, hand, upper and lower limbs), adapted from the Oxfordshire Community Stroke Project. ${ }^{14}$ The total score ranged from 4 to 16.

The proportions of $\mathrm{LBD}$ and $\mathrm{RBD}$ patients showing unilateral visual field, somatosensory and motor deficits were analysed by a Chisquare statistics. We also computed the Odds ratios (OR) and $95 \%$ confidence intervals ${ }^{1516}$ for the differences between the proportions of LBD and RBD patients showing sensory and motor deficits. Differences between the two groups in the severity of the sensory and
Table Incidence of visual half-field (VHF), somatosensory [position sense (POS) and sense of pain], and motor deficits $(M)$ contralateral to a hemispheric lesion in $R B D$ and $L B D$ stroke patients. $+1-=$ deficit present/ deficit absent. OR = Odds Ratios (95\% confidence intervals in brackets). OR values higher than 1 indicate a greater risk for $R B D$ patients, lower than 1 a greater risk for $L B D$ patients.

\begin{tabular}{|c|c|c|}
\hline & $R B D$ & $\angle B D$ \\
\hline $\begin{array}{l}\text { VHF+ } \\
\text { VHF- } \\
\text { Total }\end{array}$ & $\begin{aligned} 21(18 \%) \\
94(82 \%) \\
115\end{aligned}$ & $\begin{array}{l}8(7 \%) \\
107(93 \%) \\
115\end{array}$ \\
\hline \multicolumn{3}{|c|}{$\begin{array}{l}\text { Chi square }(d f=1)=6.67, p=0.0098 \\
\text { O.R. }=2.99(1 \cdot 19-7 \cdot 74)\end{array}$} \\
\hline $\begin{array}{l}\text { POS+ } \\
\text { POS- } \\
\text { Total }\end{array}$ & $\begin{array}{l}42(37 \%) \\
72(63 \%) \\
114\end{array}$ & $\begin{array}{l}28(25 \%) \\
86(75 \%) \\
114\end{array}$ \\
\hline \multicolumn{3}{|c|}{$\begin{array}{l}\text { Chi square }(\mathrm{df}=1)=4.04, \mathrm{p}=0.044 . \\
\text { O.R. }=1.79(0.97-3.31)\end{array}$} \\
\hline $\begin{array}{l}\text { PAIN+ } \\
\text { PAIN- } \\
\text { Total }\end{array}$ & $\begin{array}{r}69(57 \%) \\
52(43 \%) \\
121\end{array}$ & $\begin{array}{l}57(45 \%) \\
69(55 \%) \\
126\end{array}$ \\
\hline \multicolumn{3}{|c|}{$\begin{array}{l}\text { Chi square }(\mathrm{df}=1)=3.43, \mathrm{p}=0.064 \\
\text { O.R. }=1.61(0.94-2.74)\end{array}$} \\
\hline $\begin{array}{l}M+ \\
M- \\
\text { Total }\end{array}$ & $\begin{array}{l}132(95 \%) \\
7(5 \%) \\
139\end{array}$ & $\begin{array}{l}128(85 \%) \\
23(15 \%) \\
151\end{array}$ \\
\hline \multicolumn{3}{|c|}{$\begin{array}{l}\text { Chi square }(d f=1)=8 \cdot 11, p=0.0044 \\
\text { O.R. }=3.39(1 \cdot 34-9 \cdot 65)\end{array}$} \\
\hline
\end{tabular}

motor deficits were analysed by two-tailed Mann Whitney U tests.

\section{Results}

Eighty nine of 154 LBD (58\%) and 103 of 144 RBD $(71 \%)$ patients had a normal level of consciousness, scoring 14 out of 14 . Fifty one LBD patients (33\%) and 27 RBD patients (19\%) had a score between 13 and 10. Fourteen LBD patients $(9 \%)$ and 14 RBD patients (10\%) scored below 10 .

Visual field deficits were assessed in 115 of 154 LBD patients $(75 \%)$ and in 115 of 144 RBD patients (80\%). Thirty nine LBD patients (25\%) and 29 RBD patients (20\%) were not examined due to low level of vigilance or defective cooperation (severe dysphasia, confusional state). The proportions of excluded patients did not differ between the two groups (Chi square $=1 \cdot 14 ; \mathrm{df}=1 ; \mathrm{p}=$ $0 \cdot 29$ ). Position sense was assessed in 114 of 154 LBD patients (74\%) and in 114 of 144 RBD patients $(79 \%)$. Forty LBD patients (26\%) and 30 RBD patients (21\%) were not examined. The proportions of excluded patients did not differ between the two groups (Chi square $=1 \cdot 09 ; \mathrm{df}=1 ; \mathrm{p}=0 \cdot 29$ ). Sense of pain was assessed in 126 out of 154 LBD patients $(82 \%)$ and in 121 out of 144 RBD patients $(84 \%)$. Twenty eight LBD patients (18\%) and $23 \mathrm{RBD}$ patients (16\%) were not examined. The proportions of excluded patients did not differ between the two groups (Chi square $=0.26 \mathrm{df}=1 ; \mathrm{p}=$ 0.61 ). Motor deficits were assessed in 151 of 154 LBD patients (98\%) and in 139 of 144 RBD patients $(97 \%)$. The proportions of excluded patients did not differ between the two groups (Chi square $=0.66 ; \mathrm{df}=1 ; \mathrm{p}=$ 0.41 ).

The incidence of sensory and motor deficits contralateral to the lesion is shown in 
the table. Visual half-field and motor deficits, and disorders of position sense are more frequent in RBD than in LBD patients. Also deficits of sense of pain show a tendency towards a closer association with right brain damage. The severity of the visual, somatosensory and motor deficits did not differ significantly between the two groups ( $p>$ $0.05)$.

\section{Discussion}

The results of this community-based study are clear-cut. RBD patients run a greater risk to develop contralateral visual half-field, somatosensory (position sense) and motor deficits, compared with LBD patients. Deficits of sense of pain also show a tendency towards a closer association with right brain damage.

The possibility that this hemispheric asymmetry is party due to bias in patients' selection should, however, be taken into consideration. Firstly, it should be noted that these data have been collected as part of a community-based study which aimed at investigating the incidence and clinical features of stroke in Umbria, Italy. Furthermore, at the time of registration of patients the physicians participating in the study were entirely unaware of the aim of this research. Secondly, RBD patients, who showed a greater incidence of contralateral sensory and motor deficits have a better score in the Glasgow coma scale. However, this scale has a 5-item section requiring a verbal response. An extremely severe dysphasic patient with a normal level of consciousness might therefore score ten. A lower score can not be entirely attributed to dysphasia, but may also reflect impaired consciousness. The percentage of patients scoring below ten, that is, of patients with a clinical disorder of consciousness independent of dysphasia, is comparable in the two groups (LBD patients: 9\%; RBD patients $10 \%)$. The observed difference in the incidence of sensory and motor deficits cannot therefore be attributed to a lower level of consciousness of the RBD group. A second potentially relevant factor is dysphasia. The neurological assessment of a number of LBD patients could have been prevented by their lack of comprehension of the examiner's commands. Had more LBD than RBD patients been kept out of the study, the biasing effect of dysphasia would have been significant; this, however, was not the case. The percentage of patients excluded from the neurological assessment of sensory and motor deficits does not differ between the two groups. Furthermore, the hypothesis of a (so far undetected) selection bias cannot explain the observed hemispheric asymmetry in the incidence of contralateral motor deficits, as limb strength was assessed in over $95 \%$ of the patients. Finally, the hemispheric difference found by Meador et al ${ }^{17}$ in patients who had intracarotid Amytal testing cannot be attrib- uted to a selection bias. In line with the present findings, contralateral somatosensory deficits and extinction are more severe after right injection.

If a factor closely associated with right brain damage contributes to contralateral hemiplegia, hemianopia and hemianaesthesia, functional recovery may be also affected. Disorders typically associated with right hemisphere lesions, such as, perceptual-spatial deficits, neglect and denial of illness, and possibly, left hemiplegia, are regarded as negative predictors of functional outcome. In contrast, there is comparatively minor evidence that dysphasia, a disorder that is usually a result of left hemisphere damage, is a negative predictor. Studies showing left-right asymmetries in the recovery process found that a right hemisphere stroke predicts a poor outcome. ${ }^{1819}$ These observations further support the conclusion that a factor (neglect) which is known to be closely associated with right brain damage, ${ }^{20}$ underlies the more frequent incidence of left sensory and motor deficits and, perhaps, their recovery.

Supported in part by CNR and MURST grants to GV and by grants from the Regione Umbria to $S R$.

1 Heilman KM, Watson RT, Valenstein E. Neglect and related disorders. In: Heilman KM, Valenstein E, eds. Clinical neuropsychology, 2nd ed. New York: Oxford University Press, 1985:243-93.

2 Vallar G, Bottini G, Sterzi R, Passerini D, Rusconi ML. Hemianesthesia, sensory neglect and defective access to conscious experience. Neurology 1991;41:650-2.

3 Vallar G, Sandroni P, Rusconi ML, Barbieri S Hemianopia, hemianesthesia and spatial neglect: a study with evoked potentials. Neurology 1991;41:1918-22.

4 Critchley M. The parietal lobes. New York: Hafner, 1953.

5 Barbieri C, De Renzi E. Patterns of neglect dissociation. Behav Neurol 1989;2:13-24.

6 Ricci S, Celani MG, Guercini G, et al. First-year results of a community-based study of stroke incidence in Umbria, Italy. Stroke 1989;20:853-7.

7 Ricci S, Celani MG, La Rosa F, et al. SEPIVAC: a community-based study of stroke incidence in Umbria, Italy. $\mathcal{f}$ Neurol Neurosurg Psychiatry 1991;54:695-698.

8 Bamford J, Sandercock P, Dennis M, Burn J, Warlow C. Classification and natural history of clinically identifiable subtypes of cerebral infarction. Lancet 1991;337 1521-6.

9 Allen CMC. Clinical diagnosis of the acute stroke syndrome. Quart ₹ Med 1983;52:515-23.

10 Sandercock PAG, Allen CMC, Corston RN, Harrison MJG, Warlow CP. Clinical diagnosis of intracranial haemorrhage using Guy's hospital score. $B M F$ 1985; 291:1675-7.

11 Teasdale G, Jennett B. Assessment of coma and impaired consciousness. A practical scale. Lancet 1974;2:81-84.

12 Bickerstaff E. Neurological examination in clinical practice. London: Blackwell, 1973.

13 Denny-Brown D. Handbook of neurological examination and case recording. Cambridge, Mass.: Harvard University Press, 1957.

14 Bamford J, Sandercock P, Dennis M, et al. A prospective study of acute cerebrovascular disease in the community: the Oxfordshire Community Stroke Project 1981-1986. F Neurol Neurosurg Psychiatry 1988;51: 1373-80.

15 Rothman KJ. A show of confidence. N Engl f Med 1978; 299:1362-3.

16 Gardner MJ, Altman DG. Confidence intervals rather than P values: estimation rather than hypothesis testing. $B M F$ 1986;292:746-50

17 Meador KJ, Loring DW, Lee GP, et al. Right cerebral specialization for tactile attention as evidenced by

18 Jongbloed L. Prediction of function after stroke: a critical review. Stroke 1986;17:765-76.

19 Dombovy ML, Sandok BA, Basford JR. Rehabilitation for stroke: a review. Stroke 1986;17:363-9.

20 Bisiach E, Vallar G. Hemineglect in humans. In: Boller $\mathrm{F}$, Grafman J, eds. Handbook of neuropsychology, Vol 1. Amsterdam: Elsevier, 1988:195-222. 